\title{
Non-isothermal moisture migration in a GCL composite liner system
}

\author{
Mayu Tincopa ${ }^{1, *}$, Gonzalo Carnero-Guzman ${ }^{2}$ \\ ${ }^{1}$ Universidad de Ingenieria y Tecnología - UTEC, Lima, Peru \\ ${ }^{2}$ Golder Associates, Melbourne, Australia
}

\begin{abstract}
Geosynthetic Clay liners (GCLs) are used extensively in waste management facilities as part of hydraulic and gas barriers since the bentonite, active component of GCLs, possesses a low conductivity when well hydrated. GCL hydration occurs in the unsaturated regime following the water retention curve of the GCL and subsoil (wetting and drying path of the WRC of the GCL and subsoil, respectively). Moreover, the GCL hydration is controlled/governed by factors such as applied stress condition, subsoil characteristics, and weather condition (temperature). This paper numerically studied the influence of temperature in the GCL hydration. The models were conducted using Vadose/W and simulations were calibrated with experimental results and further practical scenarios were then predicted. Five temperature conditions that resemble average and extreme weather were used $\left(5^{\circ} \mathrm{C}, 10^{\circ} \mathrm{C}, 20^{\circ} \mathrm{C}, 50^{\circ} \mathrm{C}, 70^{\circ} \mathrm{C}\right.$, respectively). Results indicate that temperature influence the GCL hydration rate and the final water content achievable, which affect the final performance of the GCL.
\end{abstract}

\section{Introduction}

Geosynthetic clay liners (GCLs) are formed of a thin layer of bentonite $(5 \sim 10 \mathrm{~mm})$ enclosed between two geotextiles by needle punching. Typically, The primary resistance for fluid flow through a GCL is provided by the bentonite (typically sodium bentonite) known for its low permeability to liquids and gases when well-hydrated (Rowe (2018) [1]). Usually, GCLs are installed in the field at low gravimetric water content $(\approx 10 \%)$ on an engineered subsoil.

GCLs are often installed together with a high-density polyethylene (HDPE) geomembrane (GMB) to form a composite liner to seal the base of landfills, brine ponds, tailing dams, heap leach pads, and many other fluid containment applications (Hornsey et al. (2010) [2]; Hamawand et al. (2013) [3]; Bouazza \& Gates, (2014) [4]). One of the factors that underpins the performance of such systems is the level of hydration that the GCL can initially achieve.

Consequently, the GCL hydration process received lot of attention over the past decade (AbdelRazek \& Rowe, (2019) [5]; Acikel et al. (2018) [6]; Anderson et al. (2012) [7]; Bouazza et al. (2014a) [8], (2017a) [9]; Rayhani et al. (2011) [10]; Siemens et al. (2012) [11]). Two main findings have been established by these studies. First, the initial moisture content, type and mineralogy of the subsoil affect the rate of hydration. Second, the water retention curves of the subsoil and GCL govern the level of hydration. The GCL hydration occurs in the "unsaturated regime" of both materials (GCL and subsoil) following their corresponding water retention curve (WRC), which itself is dependent on their inherent pore structure (Acikel et al. 2018 [12]).

While the water content of GCLs increases following the wetting path, it is expected that the subsoil water content reduces until both materials reach suction equilibrium, initially at the interface GCL-subsoil, and eventually throughout the entire volume of both materials (Siemens et al. (2012) [11]).

However, the increased use of GCLs in applications where they are subjected concurrently to changes in temperature and consequently to hydration mechanisms, means that the moisture dynamics occurring in GCL composite liner systems need to account for these coupled conditions (Bouazza et al. (2014a) [8], (2017b) [13]; Ghavam-Nasiri et al. (2019) [14]; Chevrier et al. (2012) [15]).

Particularly, in some of GCL applications (e.g. brine ponds, leachate ponds heap leach pads, etc.) the GCLGMB composite liner is subjected to elevated temperatures combined. This condition can affect the hydraulic performance of GCL composite liner systems as reported by Bouazza et al. (2011) [16] (2014a) [8]; (2017b) [13]; Rowe (2018) [1].

The objective of this study is to explore numerically the moisture migration in a GCL composite liner and to establish the mechanisms governing GCL hydration under a range of temperatures $\left(5^{\circ} \mathrm{C}, 10^{\circ} \mathrm{C}, 20^{\circ} \mathrm{C}, 50^{\circ} \mathrm{C}\right.$, $70^{\circ} \mathrm{C}$, respectively). Numerical simulations were conducted to assess different cases typically encountered in practice.

\footnotetext{
* Corresponding author: mtincopa@utec.edu.pe
} 


\section{Method}

\subsection{Laboratory conditions}

The numerical model was calibrated with experimental results using an instrumented column test conducted at Monash University, Australia by Tincopa (2020) [17].

The column apparatus used in the current study was custom-made for the assessment of a composite liner system (GCL and GMB) subjected to vertical stresses up to $200 \mathrm{kPa}$ and temperatures up to $90^{\circ} \mathrm{C}$ (Figure 1) and described in detail in Bouazza et al. (2014a) [8], (2017b) [13].

The column was composed of three parts. The upper part consisted of a stainless-steel water reservoir with the top cap fitted with a coil heater. The central part consisted of a polytetrafluoroethylene (PTFE) cylinder of $100 \mathrm{~mm}$ in diameter and $400 \mathrm{~mm}$ in height, instrumented with time domain reflectometer (TDR) and thermocouple (TC). The lower part consisted of stainless-steel water reservoir at a constant temperature of $20 \pm 1^{\circ} \mathrm{C}$.

The water retention curve (WRC) of GCL (wetting) and subsoil (drying) at difference temperatures are shown in Figure 2. The WRC of the GCL and subsoil were experimentally obtained using techniques which included filter paper and osmotic technique for low suctions and chilled mirror dewpoint (WP4C dewpoint potentiometer) and vapour equilibrium technique (VET) for suctions $>3$ MPa (Tincopa \& Bouazza, 2020 [18]). Both column test results and water retention curve of GCL and subsoil were used in this study to predict GCL composite liner behaviour under high temperatures.

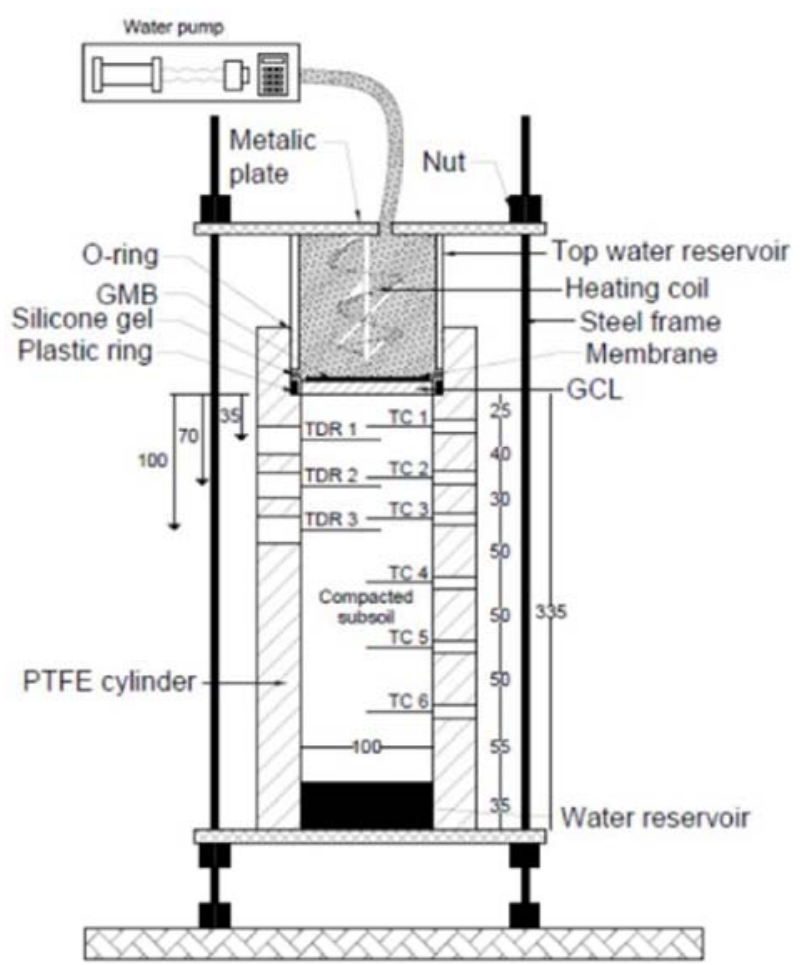

Figure 1 Schematic view of the column test (retrieved from Tincopa 2020 [17])

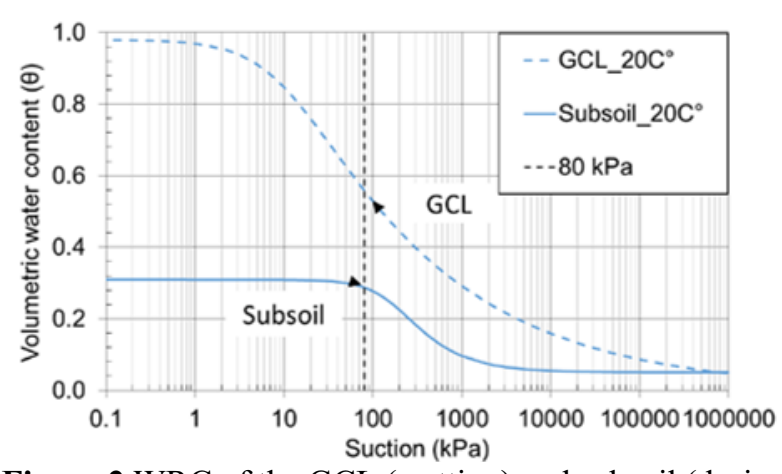

Figure 2 WRC of the GCL (wetting) and subsoil (drying) (retrieved from Tincopa 2020 [17]).

\subsection{Numerical analyses}

An axi-symmetric finite element analysis was performed using the Vadose/W software (GeoStudio, 2007) to simulate the moisture and temperature distribution obtained from the column test initial conditions. The laboratory temperature was set up at $20^{\circ} \mathrm{C}$. The initial suction of the GCL at a dry condition (i.e. at received condition) was $200 \mathrm{MPa}(\theta=0.02)$ whereas the subsoil at optimum gravimetric water content was set to $0.04 \mathrm{MPa}$ $(\theta=0.31)$. The initial suction values were estimated based on the water retention curves of both materials (Figure 2). A fixed temperature of $20^{\circ} \mathrm{C}$ was set at the bottom boundary, while different temperatures $\left(5^{\circ} \mathrm{C}, 10^{\circ} \mathrm{C}, 20^{\circ} \mathrm{C}\right.$, $50^{\circ} \mathrm{C}$ and $70^{\circ} \mathrm{C}$ ) were set at the top boundary (GMB). These boundary conditions agree with the field scenarios where the surface temperature is highly affected by the weather, leachate and brine solution, while temperature in the subsoil tends to remain steady. Finally, it was assumed that there were no radial heat losses from the vertical side boundary.

\subsection{Governing equations}

Moisture and heat transfer for saturated or unsaturated conditions can be simulated by solving differential equations. These equations are implemented in Vadose/W (GeoStudio, 2007). A brief summary of the differential equation is described below. Further details of these equations can be found in the GeoStudio Manual (Krahn (2004) [19])

\subsubsection{Moisture transfer}

In unsaturated porous media, the moisture transfer comprises of the flow of liquid water and the migration of water vapour. The following mathematical expression is based on the law of mass conservation and Darcy's law for liquid and vapour:

$$
m_{v} \frac{\partial \psi}{\partial t}=\nabla(q)+\frac{1}{\rho} \nabla\left(D_{v} \nabla \phi\right)
$$

where the $\psi$ is the suction $(\mathrm{kPa}), D_{v}$ is the vapour diffusion coefficient as described by Wilson (1990) [20], $m_{v}$ is the slope of the volumetric water content (VWC) 
function (-), and $q$ is the flow of liquid water through unsaturated soil as can be described via Darcy's law:

$$
q=\nabla\left(k_{r} k \nabla\left(\frac{\psi}{\rho g}+y\right)\right.
$$

where $\rho$ is the density of the porous media $\left(\mathrm{kg} / \mathrm{m}^{3}\right), g$ is the acceleration due to gravity $\left(\mathrm{m} / \mathrm{s}^{2}\right), y$ is the depth $(\mathrm{m})$, $k_{r}$ is the relative hydraulic conductivity (-). Olivella and Gens (2000) [21] introduced a new model for the intrinsic permeability of clay. This model assumes a constant total porosity and a single degree of saturation for the macro, micro and total porosity. These assumptions permit a simple approach because the mechanical effect is neglected, and a double porosity approach is not required. The following model represents the intrinsic permeability $(k)$ that can be defined as a function of micro and macroporosity:

$$
k=k_{0}\left(\frac{1-n_{0}}{1-n_{M}}\right)^{2}\left(\frac{n_{M}}{n_{0}}\right)^{3} I
$$

where $k_{0}$ is the saturated intrinsic permeability $\left(\mathrm{m}^{2}\right), n_{0}$ is the initial porosity (-), and the $n_{M}$ is the macro-porosity given by:

$$
n_{M}=n_{0} e^{-\beta S_{e}}
$$

where $\beta$ is a fitting coefficient (beta) that varies from 0 to 7 (high and low hydraulic conductivity soils). Low intrinsic permeability of a material requires a model that considers the highly different mobilities of gas and water. A relationship between the suction and the temperature is represented by the Psychrometric law:

$$
\phi=P_{v S}\left(e^{-\frac{\psi M_{w}}{\rho R T}}\right)
$$

where $P_{v s}$ is the saturated vapour pressure of pure free water, $M_{w}$ is the molar mass of water vapor $(\mathrm{kg} / \mathrm{mol}), R$ is the universal gas constant $(\mathrm{J} / \mathrm{mol} \mathrm{K})$, and $T$ is the temperature $\left({ }^{\circ} \mathrm{K}\right)$.

\subsubsection{Moisture transfer}

The heat transfer equation is a standard Fourier equation. This equation was formulated by considering the porous media.

$$
\left(\rho C_{p}\right)_{e f f} \frac{\partial T}{\partial t}=L_{v} \nabla\left(D_{v} \nabla \phi\right)+\nabla\left(\lambda_{e f f} \nabla T\right)
$$

where $L_{v}$ is the latent heat of vaporization and $\left(\rho C_{p}\right)_{e f f}$ is defined as the volumetric heat capacity via the following equation:

$$
\left(\rho C_{p}\right)_{e f f}=\rho_{s} C_{s}(1-n)+n S_{r} C_{w}
$$

where $C_{s}$ and $C_{w}$ are the heat capacity of the soil and water, respectively. $S_{r}$ is the degree of saturation (\%). The effective thermal conductivity is defined as follows (Farouki, (1981) [22]; Johansen, (1977) [23]:

$$
\lambda_{e f f}=\left(\lambda_{s a t}-\lambda_{d r y}\right)\left(0.85 \log \left(S_{r}\right)+1\right)+\lambda_{d r y}
$$

where $\lambda_{\text {sat }}$ and $\lambda_{\text {dry }}$ are the thermal conductivity saturated and dry, respectively. Each component can be expressed as follows:

$$
\begin{gathered}
\lambda_{\text {sat }}=\lambda_{s}^{(1-n)} \lambda_{w}^{(n)} \\
\lambda_{d r y}=\frac{0.137 \rho_{d}+64.7}{2700-0.947 \rho_{d}}
\end{gathered}
$$

where $\rho_{\mathrm{d}}$ is the dry density of the soil $\left(\mathrm{kg} / \mathrm{m}^{3}\right), \lambda_{s}$ and $\lambda_{w}$ are the thermal conductivity of soil and water (W/m.K). Solving and coupling these equations allow the simulation of thermo-hydraulic behaviour. Notably, a limitation of the software was its inability to vary the tortuosity value in the diffusion term because the default tortuosity value was equal to 1 .

\subsection{Conceptual model}

The current study simulated the same type of GCL and subsoil type as in Bouazza et al. (2017a) [9]. Numerical modelling was conducted to simulate the laboratory test and conditions (section 2.1). Three components were considered in the simulation, namely the GMB, GCL and subsoil. The following assumptions were made for the simulation:

- There is an intimate contact between the GMB, GCL and subsoil.

- There is an initial constant temperature and moisture across the components.

- The settlement due to the moisture migration is negligible and thus can be ignored.

- The tortuosity of the GCL is constant and equal to 1 . Some of these assumptions may have influenced the results to some extent. For instance, the tortuosity of the GCL may limit the speed of moisture migration. However, these limitations were mitigated by fitting the numerical results with the experimental data. Thus, a calibrated model can be developed reliably. Figure 3 presents the conceptual model and the influence of element sizes in the results. The element sizes were optimised as shown in Figure 3 and a fine distribution was used for the analyses presented herein.

\subsection{Material parameters}

The material parameters used in the numerical analysis are summarised in Table 1. The following sections describe the two governing parameters for heat and moisture transfer.

The WRC provides a moisture-suction relationship (volumetric or gravimetric). The Van Genuchten (VG) fitting equation (Eq. 11) was used to establish the WRCs of both materials van Genuchten, (1980) [24].

$$
S_{e}=\frac{\left(\theta_{\psi}-\theta_{r}\right)}{\left(\theta_{s}-\theta_{r}\right)}=\left[1+(\alpha \psi)^{n}\right]^{-m}
$$

where $\alpha, n, m$ denote the $\mathrm{VG}$ parameters, $\theta$ is the volumetric water content $\left(\mathrm{m}^{3} / \mathrm{m}^{3}\right), \theta_{s}$ and $\theta_{r}$ are the saturated and residual volumetric water content (VWC), respectively. The VG parameters were represented in 
VWC, while the GCL hydration was reported in GWC, and hence a conversion was needed. As a result, the VWC data for the WRC of a GCL was estimated based on the total volume and water uptake of the GCL. Both values were measured throughout the test (Tincopa 2020 [17]; Carnero-Guzman 2019 [25]).

$\theta=-1.22 \times 10^{-5} w^{2}+6.61 \times 10^{3} w$

The van Genuchten (1980) [24] model was fitted to the experimental values reported by Tincopa et al. (2019) [26] and Bouazza et al. (2017a) [9] for similar type of GCL and subsoil. Fitting parameters for both materials are tabulated in Table 2.

On the other hand, the numerical analysis conducted in this paper modelled heat and water transfer at five temperature conditions $\left(5^{\circ} \mathrm{C}, 10^{\circ} \mathrm{C}, 20^{\circ} \mathrm{C}, 50^{\circ} \mathrm{C}, 70^{\circ} \mathrm{C}\right.$, respectively). Thus, it is relevant to consider the influence of temperature on the WRC.

Several authors observed that the temperature influences the WRC shape at lower suctions below the air entry value. For suctions higher than the air entry value, $\psi_{\text {aev }}$, the SWRCs at different temperatures are almost parallel, indicating that the VG parameters, $m$ and $n$, are not affected by temperature (Grant \& Salehzadeh 1996 [27]; Laloui et al. 2013 [28]; Wan et al. 2015 [29]; Roshani \& Sedano 2016 [30]).

Roshani \& Sedano (2016) [30] developed a method based on the relationship between temperature and the capillary rise is applied to find the air entry value at different temperatures when its value is known at a reference temperature that can be expressed as follows:

$\alpha_{T}=\alpha_{(T=293.5)} \times 7.2252 \times 10^{-5} \times \frac{\left(658.2+2.509 T-4.606 \times 10^{-3} \times T^{2}\right)}{(0.117-0.000153 T)}$

where $\alpha_{T}$ and $\alpha_{(T=293.5)}$ are $\alpha \mathrm{VG}$ parameters at target temperature and $20^{\circ} \mathrm{C}$, respectively, and $T$ is the target temperature (all in Kelvin). By using Eq. 13, $\alpha$ of GCL and subsoil was calculated for each temperature and results are shown in Table 2.

The effect of temperature did not change the shape of the WRC considerably, which is in agreement with results presented in the literature. $\alpha \mathrm{VG}$ parameters for each temperature will be used in the corresponding numerical analysis.

The unsaturated hydraulic function for the GCL can be estimated using $k_{r}=S_{e}^{12}$. This relationship was used for bentonite in previous studies (Olivella and Gens, 2000 [21]; Wang et al. 2011 [31]) because the moisture movement in bentonite was controlled by vapour movement. The $k_{r}=S_{e}{ }^{3}$ relationship was considered for the subsoil since the moisture movement in the silty sand was controlled by the capillarity movement.

Additionally, the $\beta$ value for the macro porosity was considered to be equal to 0.5 and 0 for the GCL and the subsoil, respectively, which aligned with previous studies (Olivella and Gens, 2000 [21]; Wang et al. 2011 [31]).

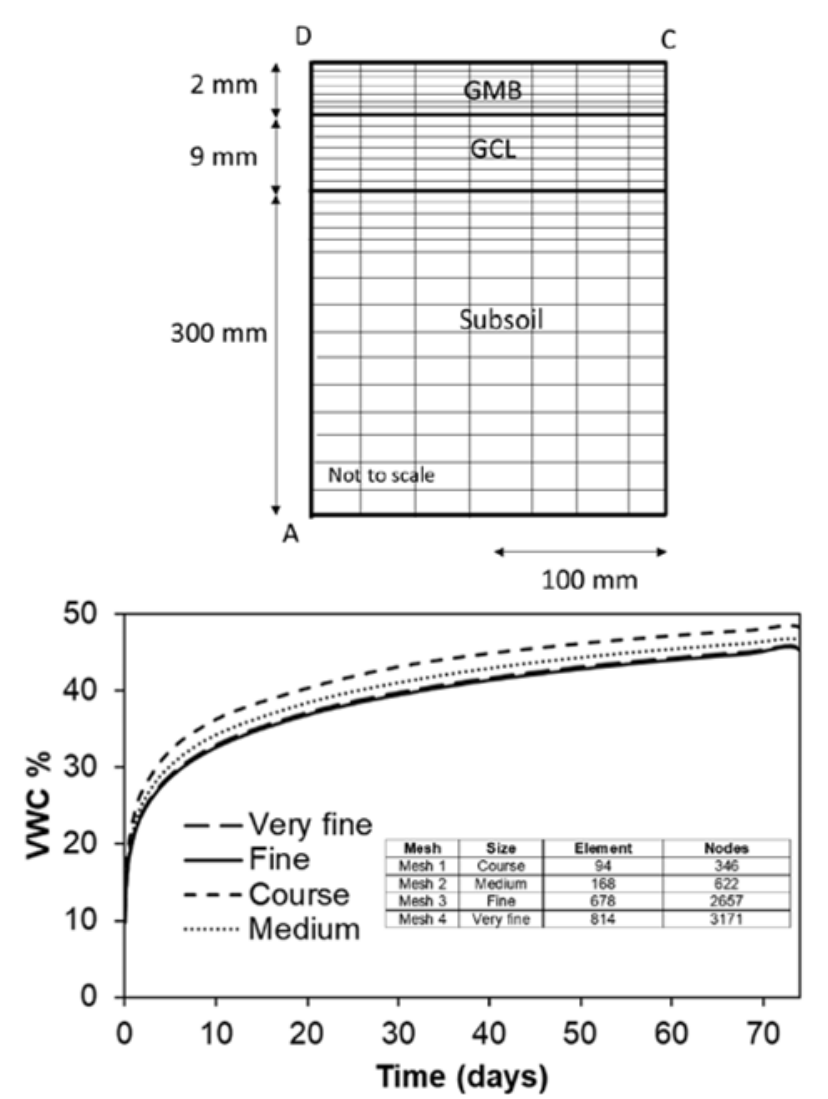

Figure 3 Conceptual model of the column test as modelled.

Table 1. Summary of material parameters used for numerical modelling.

\begin{tabular}{|c|c|c|c|c|c|}
\hline Parameter & Symbol & Units & GMB & $\begin{array}{c}\text { GCL } \\
\text { Wetting }\end{array}$ & $\begin{array}{l}\text { Subsoil } \\
\text { Drying }\end{array}$ \\
\hline $\begin{array}{l}\text { Saturated } \\
\text { intrinsic } \\
\text { permeability }\end{array}$ & $k_{0}$ & $\mathrm{~m}^{2}$ & $\begin{array}{c}1 \times 10^{-} \\
18\end{array}$ & $3 \times 10^{-11}$ & $1 \times 10^{-8}$ \\
\hline $\begin{array}{l}\text { Relative } \\
\text { hydraulic } \\
\text { conductivity } \\
\text { fitting }\end{array}$ & $k_{r}$ & - & - & $\mathrm{Se}^{12}$ & $\mathrm{Se}^{3}$ \\
\hline $\begin{array}{l}\text { coefficient } \\
\text { (beta) }\end{array}$ & $\beta$ & - & - & 0.5 & 0 \\
\hline $\begin{array}{l}\text { Saturated } \\
\text { volumetric } \\
\text { content }\end{array}$ & $\theta_{s}$ & $\underset{3}{\mathrm{~m}^{3} / \mathrm{m}}$ & - & 0.98 & 0.31 \\
\hline $\begin{array}{l}\text { Residual } \\
\text { volumetric } \\
\text { content }\end{array}$ & $\theta_{r}$ & $\underset{3}{\mathrm{~m}^{3} / \mathrm{m}}$ & - & 0.001 & 0.05 \\
\hline Van & $\alpha$ & $1 / \mathrm{m}$ & - & 1 & 0.055 \\
\hline Genuchten at & $\mathrm{n}$ & - & - & 1.25 & 2 \\
\hline $20^{\circ} \mathrm{C}$ & $\mathrm{m}$ & - & - & 0.21 & 0.50 \\
\hline $\begin{array}{c}\text { Thermal } \\
\text { conductivity } \\
*\end{array}$ & $\lambda$ & $\stackrel{\mathrm{W} / \mathrm{m}}{{ }^{\circ} \mathrm{C}}$ & 0.35 & $\lambda_{1}(\theta)$ & $\lambda_{2}(\theta)$ \\
\hline $\begin{array}{l}\text { Specific heat } \\
\text { capacity* }\end{array}$ & $C_{p}$ & $\begin{array}{c}\mathrm{J} / \mathrm{kg} \\
\mathrm{K}\end{array}$ & - & $C_{p_{3}}(\theta)$ & $C_{p_{4}}(\theta)$ \\
\hline
\end{tabular}

Table 2. $\alpha(k P a) \mathrm{VG}$ values for each target temperature. 


\begin{tabular}{cccccc}
\hline \multirow{2}{*}{ Material } & \multicolumn{5}{c}{ Temperature $\left({ }^{\circ} \mathbf{C}\right)$} \\
\cline { 2 - 6 } & $\mathbf{5}$ & $\mathbf{1 0}$ & $\mathbf{2 0}$ & $\mathbf{5 0}$ & $\mathbf{7 0}$ \\
\hline GCL & 0.970 & 0.979 & 1 & 1.056 & 1.093 \\
Subsoil & 176.28 & 178.04 & 181.81 & 191.97 & 198.79 \\
\hline
\end{tabular}

\section{Results and Discussion}

\subsection{Calibration of the model}

Once the numerical model was built, based on the experimental conditions and the material properties, a parametric analysis was conducted to match the experimental results reported by Tincopa M. (2020) [17]. The volumetric difference $(\Delta \theta)$ between initial $\left(\theta_{\text {ini }}\right)$ value and value at any other time $\left(\theta_{t}\right)$ against time $(\mathrm{t})$ was compared to the numerical analyses as shown in Figure 4. The best match between experimental and numerical result were found at beta equal to 0.5 for the GCL at $20^{\circ} \mathrm{C}$. This value is consistent with the literature (Olivella and Gens (2000) [21]; Wang et al. 2011 [31]).

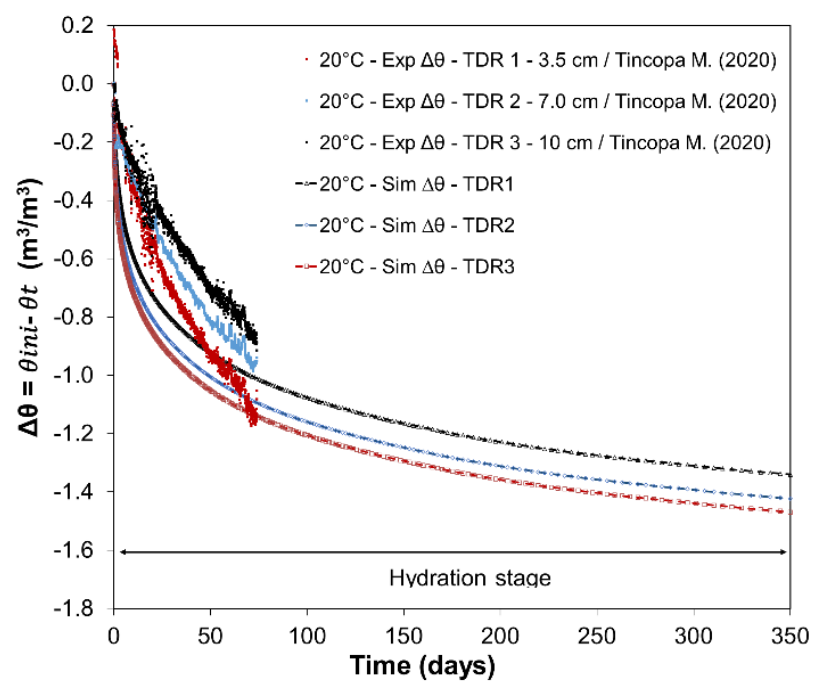

Figure 4 The volumetric difference in the subsoil $\Delta \theta$ vs time at distance of $3.5,7.0$ and $10 \mathrm{~cm}$ from the GCL.

\subsection{Prediction of moisture migration into the subsoil}

Based on the calibration model using experimental data (section 3.1), a set of numerical analysis were conducted to evaluate the effect of temperature on the moisture migration into the subsoil.

Figure 5 shows the variation of the subsoil VWC against time. The increases and decreases of $\Delta \theta$ describe the gains and losses of water in the subsoil. Figure 5 also shows that overtime, the moisture loss of the $\Delta \theta$ measured by TDR 1 , at a depth of $3.5 \mathrm{~cm}$, was greater than the $\Delta \theta$ measured by TDR 3 , at a depth of $10 \mathrm{~cm}$. This is likely to be due to TDR 1 being closer to the GCL, and therefore the suction interaction was stronger.

Figure 5 (only numerical analysis) shows that, after 350 days of the hydration stage, moisture equilibrium is only attained at $50^{\circ} \mathrm{C}$ and $70^{\circ} \mathrm{C}$, but lower temperature seems to require more time to reach equilibrium.

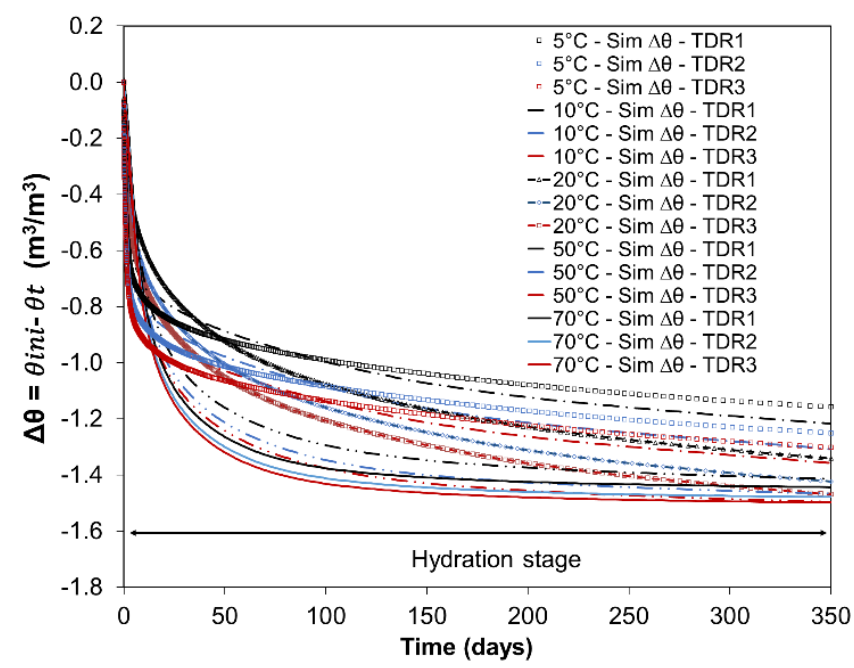

Figure 5 A prediction moisture migration of the subsoil at differences temperatures.

\subsection{Prediction of moisture migration into the GCL}

The hydration processes of the GCL were captured in the numerical simulation as shown in Figure 6. Several predictions at different temperatures during the hydration of GCL can be made using the numerical tool under similar field conditions (e.g. same GCL and subsoil).

Figure 6 shows the changes in VWC during GCL hydration against time, predicted numerically and compared to the experimental results from the studies reported by Tincopa (2020) [17] and Bouazza et al. (2017a) [9]. Water uptake from subsoil to GCL hydration occurs firstly as vapour and then as liquid phase. Based on the model results, water uptake seems to move rapidly as the gradient in temperature increased among both materials. The vapour phase mobility increased as the gradient in temperature increased, as it can be presented on Eq. 1 and 5,

Interestingly, the numerical results indicated that the higher the applied temperature, the faster the final volumetric content of GCL was reached. Low temperatures took more time to reach equilibrium. nevertheless, it seems that at the beginning of the hydration (within 75 days), the gradient of temperature between the GCL and the subsoil accelerated the moisture migration as it can be seen in Figure 6.

The numerical prediction of the GCL hydration captures satisfactorily the experimental trend. Moreover, it follows the same trend as the one reported by Bouazza et al (2017a) [9] for a continuous hydration which lasted close to 80 days. The difference observed in this latter is due to the fact that in the experiment reported by Bouazza et al (2017a) [9] the GCL specimen was removed from the column on a weekly basis to measure its weight, thus, breaking of capillarity between the GCL and the subsoil occurred. The numerical simulation presented herein did not consider this break of the capillarity. Consequently, the simulation overestimated the VWC of the GCL over the hydration period. 
Finally, results also shown that higher temperatures than $20^{\circ} \mathrm{C}$ will lead to higher final GCL VWC $(0.56$ $\mathrm{m}^{3} / \mathrm{m}^{3}$ ), which imply a better performance of the barrier. On the contrary, lower temperatures than $20^{\circ} \mathrm{C}$ will lead to lower final GCL VWC $\left(0.54 \mathrm{~m}^{3} / \mathrm{m}^{3}\right)$, which must be taken into consideration in GCL applications.

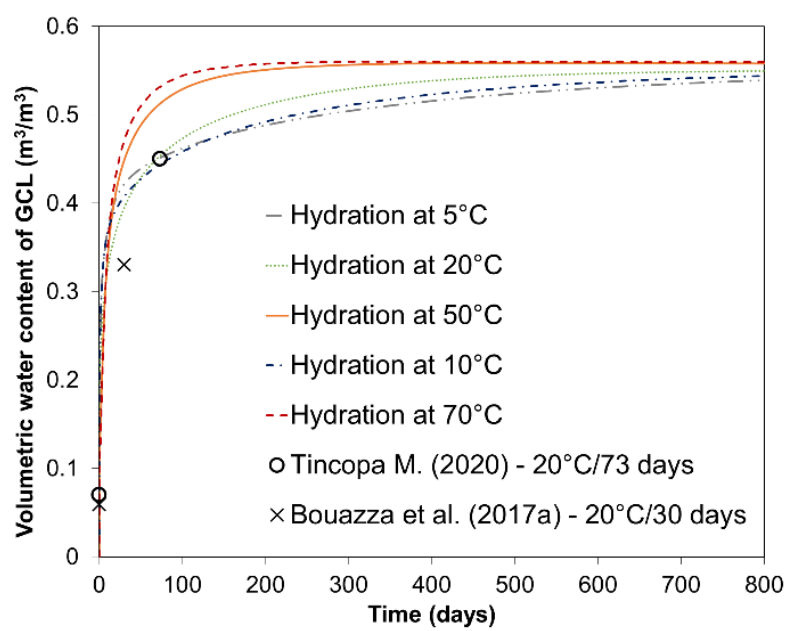

Figure 6 Prediction of the changes in VWC during GCL hydration against time.

\subsection{Prediction of final GCL VWC for different subsoil suction}

The final water content in the GCL depends on the initial suction existing in the soil at the start of the hydration process. Thus, an analysis can be performed by varying the initial suction in the soil and obtaining the corresponding final water content in the GCL. Figure 7 shows the final GCL water content against the initial soil water content represented by the dashed line referred to as "prediction line" which can be obtained for each studied temperature (lines for $5^{\circ} \mathrm{C}, 20^{\circ} \mathrm{C}$ and $70^{\circ} \mathrm{C}$ are shown in Figure 7).

Also, the saturation for the GCL is indicated. A degree of saturation $S_{r}^{*}=w / w_{\text {ref }}=80 \%$ is commonly recommended to assure an effective performance of the GCL as a hydraulic barrier (e.g. Siemens et al. 2012 [11]; Rowe, 2014 [32]). For the studied GCL, $S_{r}^{*}=80 \%$ value is $0.784 \mathrm{~m}^{3} / \mathrm{m}^{3}$. However, Bouazza et al. (2017a) [9] considered that the GCL should attain a minimum of $S_{r}^{*}=$ $50 \%$ to minimise a possible adverse impact on the hydraulic performance. For the studied GCL, $S_{r}^{*}=80 \%$ value is $0.49 \mathrm{~m}^{3} / \mathrm{m}^{3}$. Both recommended degrees of saturations are shown as dotted arrows in Figure 7.

Based on the analysis, it was found that, at different temperatures, there is a small change on the prediction line for the temperature range between $5^{\circ} \mathrm{C}$ to $70^{\circ} \mathrm{C}$.

On the other hand, the prediction lines indicate that a constant increment on GCL moisture content occurs when the initial VWC of subsoil is greater than $0.05 \mathrm{~m}^{3} / \mathrm{m}^{3}$, which corresponds to $2.5 \% \mathrm{GWC}$.

Also, Figure 7 shows that the studied subsoil is unable to hydrate the GCL up to the recommended $S_{r}^{*}=80 \%$. However, if the minimum $S_{r}^{*}=50 \%$ is taken into account, then the GCL can attain the minimum recommended value when the VWC of the subsoil is
$0.265 \mathrm{~m}^{3} / \mathrm{m}^{3}$, which corresponds to $15.5 \% \mathrm{GWC}$. Hence, one can infer that this water content is the minimum recommended value needed to hydrate the GCL to the target of $50 \%$ saturation in the current investigation under the studied temperature range.

Similar plots like Figure 7 can be constructed using numerical models and used to predict the equilibrium GCL water content for several target temperatures. However, for GCLs and subsoils other than the ones studied in this investigation, experimental data are required before the application of a predictive model. Interestedly, Figure 7 shows that initial soil VWC lower than $0.05 \mathrm{~m}^{3} / \mathrm{m}^{3}$ does not have any effect on the GCL as moisture migration no longer occurs.

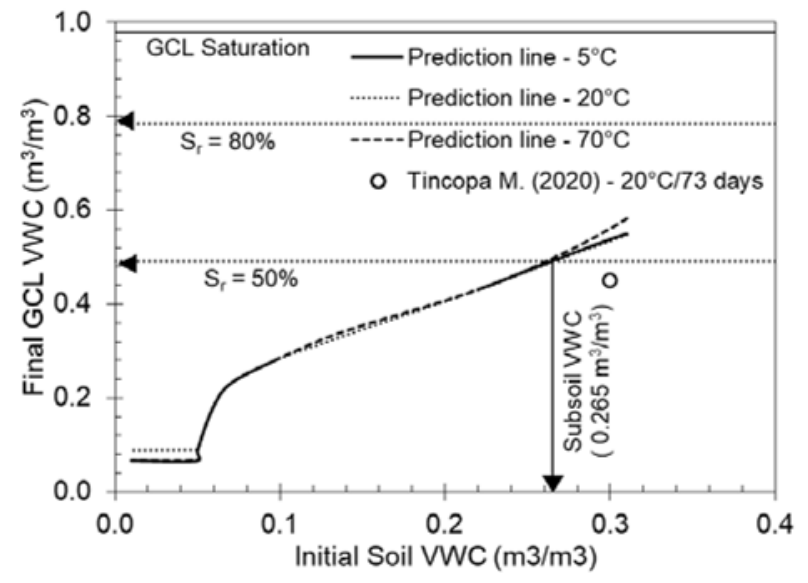

Figure 7. Final GCL water content in function of the initial soil water content and compared with saturation conditions and $\mathrm{Sr}^{*}=80 \%$ and $\mathrm{Sr}^{*}=50 \%$ which are minimum saturations recommended in the literature.

\section{CONCLUSIONS}

The coupled thermo-hydraulic (TH) behaviour of a GCL composite liner has been examined under elevated temperature. The focus was on the $\mathrm{TH}$ behaviour during the hydration stage. The following conclusions to be drawn from the current work:

- Moisture migration from the subsoil to the GCL is due to the difference in suction and temperature between the subsoil and the GCL.

- Numerical simulation confirmed the experimental results based on the WRC of the subsoil and GCL under the investigated conditions.

- The moisture in the form of a vapour and liquid seems to move rapidly from the subsoil to the GCL as the gradient in temperature increased.

- Higher temperatures than $20^{\circ} \mathrm{C}$ will lead to higher final GCL VWC $\left(0.56 \mathrm{~m}^{3} / \mathrm{m}^{3}\right)$, whereas lower temperatures than $20^{\circ} \mathrm{C}$ will lead to lower final GCL VWC $\left(0.54 \mathrm{~m}^{3} / \mathrm{m}^{3}\right)$, which must be taken into consideration in GCL applications in cold environments.

- Using the prediction lines based on a relationship between the initial soil water content and the GCL final water content, it was established that an initial soil volumetric water content of $0.265 \mathrm{~m} 3 / \mathrm{m} 3$ would 
ensure a GCL degree of saturation $w / w_{\text {ref }}=50 \%$ for all the studied temperatures.

\section{Acknowledgements}

This research project is supported by the Australian Research Council's Linkage Projects funding scheme (project number LP140100516). The authors also acknowledge the Peruvian National Program of Scholarships and Student Loans (PRONABEC) for the funding support provided to the second author. The authors are very grateful for Professor Malek Bouazza's contributions on this study.

\section{References}

1. R. K. Rowe (2020). Geosynthetic clay liners: perceptions and misconceptions. Geotextiles and Geomembranes, 48(2),137-156, https://doi.org/10.1016/j.geotexmem.2019.11.012

2. W. P. Hornsey, J. Scheirs W. P. Gates, \& A. Bouazza (2010). The impact of mining solutions/liquors on geosynthetics. Geotextiles and Geomembranes, 28(2), 191-198,

https://doi.org/10.1016/j.geotexmem.2009.10.008

3. I. Hamawand, T. Yusaf \& S.G. Hamawand (2013). Coal seam gas and associated water: a review paper. Renewable and Sustainable Energy Reviews, 22, 550-560. https://doi.org/10.1016/j.rser.2013.02.030

4. A. Bouazza \& W.P. Gates (2014). Overview of performance compatibility issues of GCLs with respect to leachates of extreme chemistry. Geosynthetics International, 21(2), 151167. https://doi.org/10.1680/gein.14.00006

5. A. Y. AbdelRazek \& R. K. Rowe. (2019). Interface transmissivity of conventional and multicomponent GCLs for three permeants. Geotextiles and geomembranes, 47(1), 60-74. https://doi.org/10.1016/j.geotexmem.2018.10.001

6. A. S. Acikel, W. P. Gates, R. M. Singh, A. Bouazza \& R. K. Rowe (2018). Insufficient initial hydration of GCLs from some subgrades: factors and causes. Geotextiles and Geomembranes, 46(6), 770781.

https://doi.org/10.1016/j.geotexmem.2018.06.007

7. R. Anderson, M. T. Rayhani \& R. K. Rowe (2012). Laboratory investigation of GCL hydration from clayey sand subsoil. Geotextiles and Geomembranes, 31, 31-38. https://doi.org/10.1016/j.geotexmem.2011.10.005

8. A. Bouazza, R. M. Singh, R. K. Rowe \& F. Gassner (2014). Heat and moisture migration in a geomembrane-GCL composite liner subjected to high temperatures and low vertical stresses. Geotextiles and Geomembranes, 42(5), 555563.

https://doi.org/10.1016/j.geotexmem.2014.08.002

9. A. Bouazza, M. A. Ali, W. P. Gates \& R. K. Rowe (2017). New insight on geosynthetic clay liner hydration: the key role of subsoils mineralogy. Geosynthetics International, 24(2), 139150. https://doi.org/10.1680/jgein.16.00022

10. M. T. Rayhani, R. K. Rowe, R. W. I. Brachman, W. A. Take \& G. Siemens (2011). Factors affecting GCL hydration under isothermal conditions. Geotextiles and Geomembranes, 29(6), 525-533. https://doi.org/10.1016/j.geotexmem.2011.06.001

11. G. Siemens, W. A. Take, R. K. Rowe, \& R. W. I. Brachman (2012). Numerical investigation of transient hydration of unsaturated geosynthetic clay liners. Geosynthetics International, 19(3), 232-251. https://doi.org/10.1680/gein.12.00011

12. A. S. Acikel, W. P. Gates, R. M. Singh, A. Bouazza, \& R. K. Rowe (2018). Insufficient initial hydration of GCLs from some subgrades: factors and causes. Geotextiles and Geomembranes, 46(6), 770781. https://doi.org/10.1016/j.geotexmem.2018.06.007

13. A. Bouazza, M. A. Ali, R. K. Rowe, W. P. Gates \& A. El-Zein (2017). Heat mitigation in geosynthetic composite liners exposed to elevated temperatures. Geotextiles and Geomembranes, 45(5), 406-417. https://doi.org/10.1016/j.geotexmem.2017.05.004

14. A. Ghavam-Nasiri, A. El-Zein, D. Airey \& R. K. Rowe (2019). Water retention of geosynthetics clay liners: Dependence on void ratio and temperature. Geotextiles and Geomembranes, 47(2), 255-268.

https://doi.org/10.1016/j.geotexmem.2018.12.014

15. B. Chevrier, D. Cazaux, G. Didier, M. Gamet, \& D. Guyonnet (2012). Influence of subgrade, temperature and confining pressure on GCL hydration. Geotextiles and Geomembranes, 33, 1-6. https://doi.org/10.1016/j.geotexmem.2012.02.003

16. A. Bouazza, J. Zornberg, J. S. McCartney, \& R.M. Singh (2013). Unsaturated geotechnics applied to geoenvironmental engineering problems involving geosynthetics. Engineering geology, 165, 143-153. https://doi.org/10.1016/j.enggeo.2012.11.018

17. M. Tincopa Heredia (2020): Experimental and numerical studies of moisture movements through a GCL composite liner under elevated temperatures and low/high confining stresses. Monash University. Thesis. https://doi.org/10.26180/5ebb333b19048

18. M. Tincopa \& A. Bouazza (2020). Water retention curves of geosynthetic clay liners under non-uniform temperature-stress paths. Geomembrane \& Geotextiles. In press.

19. J. Krahn (2004). Geostudio tutorials.

20. G. W. Wilson (1990). Soil evaporative fluxes for geotechnical engineering problems (Doctoral dissertation, University of Saskatchewan).

21. S. Olivella \& A. Gens (2000). Vapour transport in low permeability unsaturated soils with capillary effects. Transport in Porous Media, 40(2), 219-241. https://doi.org/10.1023/A:1006749505937 
22. O. T. Farouki (1981). The thermal properties of soils in cold regions. Cold Regions Science and Technology, 5(1), 67-75. https://doi.org/10.1016/0165-232X(81)90041-0

23. O. Johansen (1977). Thermal conductivity of soils. Cold Regions Research and Engineering Lab Hanover NH. https://doi.org/10.1016/0165232X(81)90041-0

24. M. T. Van Genuchten (1980). A closed-form equation for predicting the hydraulic conductivity of unsaturated soils. Soil science society of America journal, 44(5), 892-898.

25. G. G. Carnero-Guzman, (2019): Hydraulic behaviour of geosynthetic clay liners under polar climate conditions. Monash University. Thesis. https://doi.org/10.26180/5dc384fba2b80

26. M. Tincopa, A. Bouazza, R. K. Rowe \& H. Rahardjo, (2020). Back-analysis of the water retention curve of a GCL on the wetting path. Geosynthetics International 2020 27:5, 523-537. https://doi.org/10.1680/jgein.20.00016

27. S. A. Grant, \& A. Salehzadeh (1996). Calculation of temperature effects on wetting coefficients of porous solids and their capillary pressure functions. Water Resources Research, 32(2), 261-270. https://doi.org/10.1029/95WR02915

28. L. Laloui, S. Salager, \& M. Rizzi (2013). Retention behaviour of natural clayey materials at different temperatures. Acta Geotechnica, 8(5), 537-546. https://doi.org/10.1007/s11440-013-0255-2

29. M. Wan, W. M. Ye, Y. G. Chen, Y. J. Cui \& J. Wang, (2015). Influence of temperature on the water retention properties of compacted GMZ01 bentonite. Environmental Earth Sciences, 73(8), 4053-4061. https://doi.org/10.1007/s12665-0143690-y

30. P. Roshani \& J. Á. I. Sedano (2016). Incorporating temperature effects in soil-water characteristic curves. Indian Geotechnical Journal, 46(3), 309-318. https://doi.org/10.1007/s40098-016-0201-y

31. W. Wang, J. Rutqvist, U. J. Görke, J. T. Birkholzer, \& O. Kolditz (2011). Non-isothermal flow in low permeable porous media: a comparison of Richards' and two-phase flow approaches. Environmental Earth Sciences, 62(6), 11971207. https://doi.org/10.1007/s12665-010-0608-1 